\title{
POSITION
}

\section{EN ROBOT PÅ OPERATIONSSTUEN}

Om synæstesi, haptisk syn og teknologidesign

\section{PERLE MØHL}

I robotkirurgiensemblet, hvor menneske og robot smelter sammen og bliver til en kirurgisk cyborg, og hvor de menneskelige færdigheder er teknologisk forbedrede og omvendt, er kirurgens sanselige inputs samtidig væsentligt begrænsede af maskinens konfiguration. Dette får kirurgdelen i ensemblet til at udvikle nye, sanselige evner: De lærer at føle med øjnene.

\section{Empiri}

På et hospital i Region Hovedstaden opererer kirurger og robotter sammen. Der er fire robotter i brug på operationsstuerne (og omtrent 30 kirurger), og en ældre robotmodel bruges til træning og simulering i kælderen. ${ }^{1}$ Robotterne på hospitalet er alle „da Vinci“-robotter, produceret af det amerikanske firma, Intuitive, som indtil videre har monopol på kirurgiske robotter. „Men der er andre, der bider dem i hælene, " fortæller Niels, chefurolog og erfaren robotkirurg. Han og operationssygeplejerske Emma underviser kirurger og kirurgiske sygeplejersker i robotkirurgi. Under træningsprogrammet lærer deltagerne blandt andet at pakke robottens arme ind i særlige (og særligt dyre) engangsdraperinger, at køre robotten med dens lange, tunge arme i stilling ved operationslejet og at føre robotinstrumenterne ind igennem ,porte“ $i$ en fantompatients neoprenmaveskind. (Fantompatienten er en plastiktorso iført en våddragt, hvilket mest af alt får patienten til at ligne en arm- og benløs livredder). Når alting er på plads, begynder kursisterne at øve sig $i$ at styre robotten og skiftes ved operationskonsollen, så alle får prøvet, hvordan det er at sidde ved konsollen, langt fra operationsbordet og holdet. De lærer også at afinstallere alting meget hurtigt, hvis noget skulle gå galt, og der akut skal skiftes til åben kirurgi. 
Mens resten af teamet står ved operationsbordet, som de plejer, skiftes deltagerne til at sidde ovre i konsollen to-tre meter fra patienten. Her kan de med håndcontrollere og fodpedaler bevæge både robotarmene og kameraet, skifte mellem instrumenter, se og navigere i plastikpatientens bughule og lave sting på et kunstigt organ: en silikonepude placeret inde i patienten.

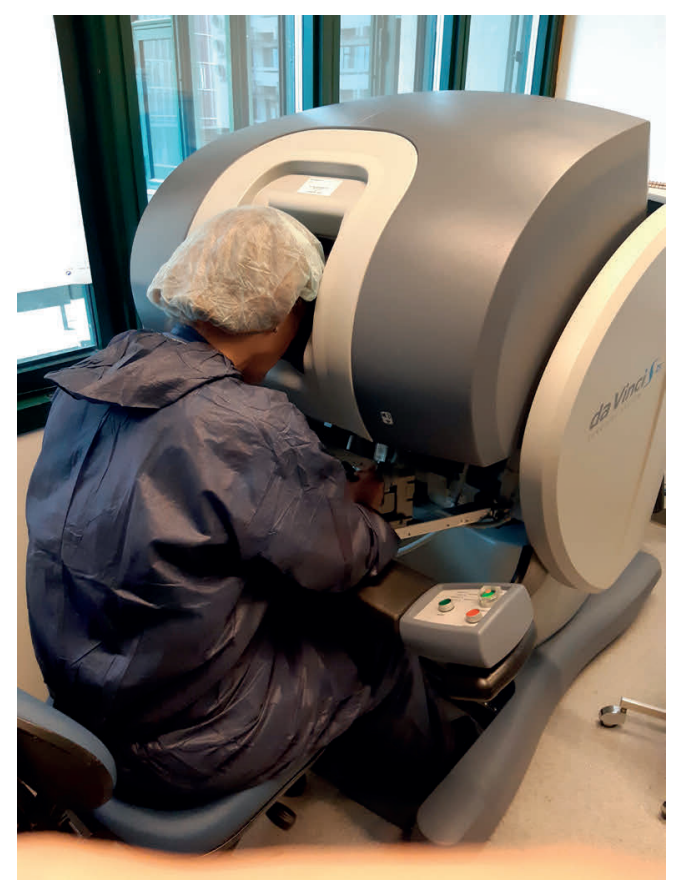

Efter en dags træning på fantompatienten går de videre til et levende emne -, ,grisetræning" - og her bliver tingene meget mere naturtro og opgaverne mere risikable. Der er anæstesi, hjertemonitor, blødninger og rigtige organer, der kan blive skadet, og der er en reel risiko for at dræbe ,patienten“. Fra konsollen lærer de at finde vej inde $\mathrm{i}$ kroppen og identificere væv og organer gennem kameraet; de udfører operationelle indgreb såsom at adskille bindevæv og skære i og helt eller delvist at fjerne organer, at afsondre blodkar og nerver og stoppe blødninger ved at brænde eller sætte klemmer på kar med robottens små hænder. Alt dette er for kirurgernes vedkommende handlinger, de har udført før - men nu skal de udføres på afstand, i samspil med robottens arme og hænder, og ved udelukkende at kunne se indgrebsområdet og patienten i nærbillede igennem det endoskopiske kamera. De har intet haptisk feedback, og kommunikationen med resten af holdet er ret begrænset, fordi kirurgen sidder med ansigt og ører helt inde i konsollen.

Den visuelle oplevelse - udsynet, skarpheden, farverne - er til gengæld fænomenal. Det er 3D - endda 3DHD i den nyeste version - og man kan fornemme dybde 
og relative afstande, man kan bevæge sig rundt, åbne sprækker, tage fat i nerve- og karbundter og skubbe væv og organer til side med de små robothænder. Kameraet er udstyret med en lampe og arbejder med en faktor-10-forstørrelse. Man er midt i handlingen så at sige. ,Se der, en arterie, der står og pumper - vi skal ind bag den og rundt om det der fedtvæv, så er vi ved at være der. Det er nok pancreashalen, der stikker frem derovre, pas på. Og der er milten inde bagved, du må endelig ikke røre den, så har vi balladen." Vi følger en binyreoperation på den store skærm på væggen i fuld farve. Bevægelserne af hænderne i bughulen minder mest af alt om en miniaturearkæolog eller opdagelsesrejsende, der gradvist bevæger sig fremad, skærer og hugger sig vej og søger efter åbninger (i junglen), i et subjektivt closeup. Billedet producerer en fornemmelse af intimitet og umiddelbarhed, en meget mærkværdig følelse af at være der, dér midt inde i patientens krop, blandt alle karrene og nerverne og bindevævet. Sætter vi mon fodspor?

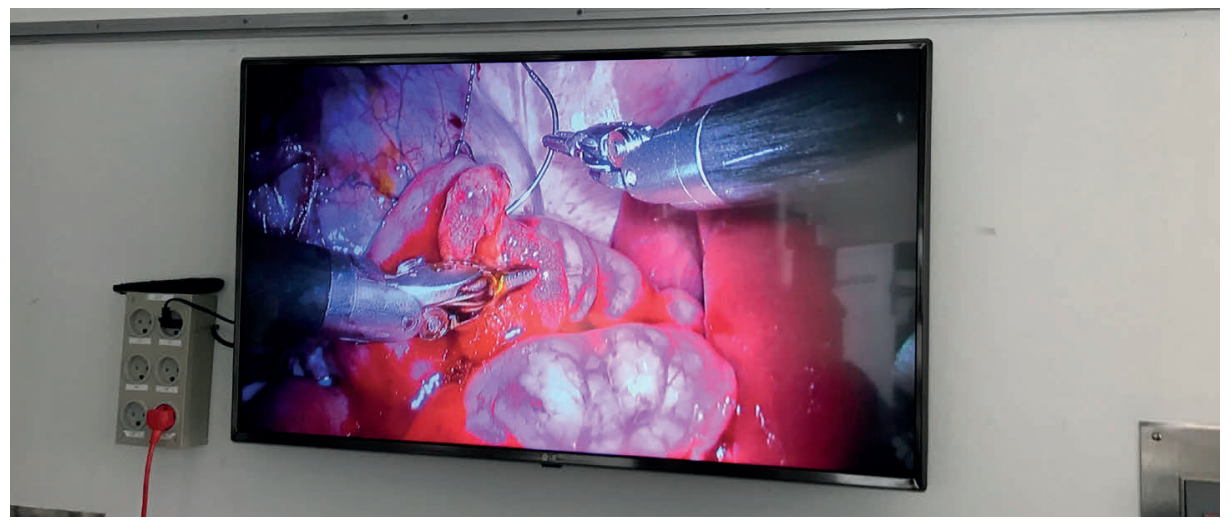

Selv om kirurgiske robotter oprindeligt blev bygget til teleoperationer (og som så megen anden teknologi til militære teleoperationer), er kirurgkonsollerne $\mathrm{i}$ på dette hospital placeret inde på operationsstuerne som sagt ca. to-tre meter fra operationsbordet. Robotsystemet er udstyret med et tovejskommunikationssystem med mikrofoner og højttalere i begge ender. Men lydkvaliteten er ikke altid optimal, og systemet bliver ofte slukket, fordi det forstyrrer mere, end det gavner. Så kirurgerne kan kun vagt høre diskussioner, kommentarer og lyde fra operationsområdet. For at kommunikere med teamet er de ofte nødt til at løfte hovedet helt fra konsollen og hæve stemmen, og så bliver robotten automatisk immobiliseret, og operationen standser. Kommunikationen er dermed stort set reduceret til højlydt, direkte tale - alt andet går tabt.

Så kirurgerne arbejder relativt isoleret, langt fra resten af holdet og patienten, med de komplikationer, det kan give. Men de taler også om øget præcision og koncentration, og nogle indrømmer, at de faktisk kan lide den afstand og isolation, som opstår, når robotten er med. De kan arbejde i timevis uden at blive 
trætte. Robotarmene fjerner endda eventuelle smårystelser fra hænderne, som kan opstå, når de har siddet der længe. Selv om robotten ikke er intelligent eller automatiseret og dermed ikke er en selvkørende robot i den klassiske forstand, er der noget bionisk over dette kirurg-robot-væsen, hvor robottens mange arme, 3DHD-syn, umådelige kræfter og stabilitet smelter sammen med den menneskelige krop og sanser og forbedrer kirurgens syn, præcision og udholdenhed.

Når man sidder i konsollen og kigger ned gennem den stereoskopiske 3Dsøger og ind i patientens bughule eller bækken, bevæger de små robotinstrumenter sig ligesom ens egne hænder: De kan dreje $360^{\circ}$, gribe væv og nåle og skære og lave sting. Deres placering i søgeren svarer til, hvor ens egne kødelige hænder klemmer om kontrollerne bag søgeren, så de fremstår grangiveligt, som var de ens egne hænder. Det hele er meget intuitivt, som virksomhedsnavnet også antyder. Og det kan jeg sige, for jeg har siddet i konsollen og deltaget i træningsprogrammer med simulering og operation på et levende testemne. Robothænderne er mere end et værktøj eller en forlængelse af ens krop. De overtager faktisk i ens bevidsthed ens egne armes og hænders plads og gøren og laden, præcis som en protese. Og med større og større overbevisningskraft fremstår robotensemblet som en cyborg - også for tilskueren, som følger dens færd på storskærmen.

Men præcis som med en protese, mangler der noget vigtigt: følelsen af berøring. Protesehænderne har ingen følesans og sender ikke noget haptisk feedback til resten af kroppen, og dermed har kirurgen overhovedet ingen haptisk fornemmelse for, hvad hun rører ved med sine små metalhænder. Og fordi robothænderne er så ualmindelig stærke og kan gennembore organer og flænse kar og nerver med et lille klem af en pegefinger i fingercontrollerne, kræver det ekstrem opmærksomhed på ens bevægelser inde i patientens indre. Den manglende følesans bliver betragtet som en særlig udfordring i uddannelsen af robotkirurger og deres senere praksis, både på danske hospitaler og i medicinsk forskning generelt (fx Bethea et al. 2004; Rangarajan et al. 2020). Siden de første robotter blev markedsført i de tidlige 2000'ere, har der derfor været stadige forsøg på at finde teknologiske løsninger på problemet, fx små buzzere i fingerkontrollerne eller visuelle signaler på skærmen (se fx. Culmer et al. 2020; Desai 2013; Ehrampoosh et al. 2013; Bethea et al. 2004), men ingen af disse løsninger har endnu været tilfredsstillende, blandt andet på grund af for lang elektronisk reaktionstid (Culmer et al. 2020). Udviklerne lover, at med 5G vil hastighedsproblemet blive løst ... 


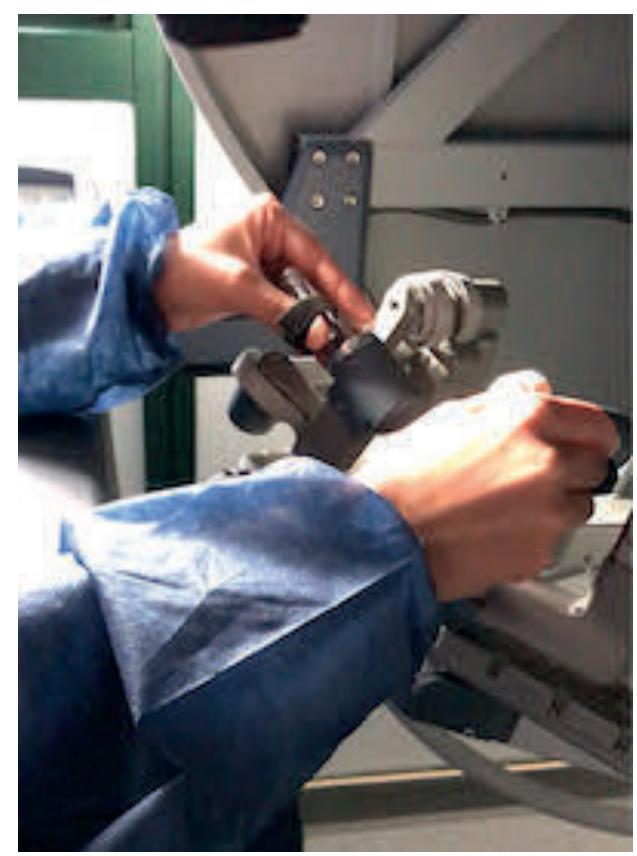

\section{Analyse}

Så kirurgen i konsollen kan ikke føle, hvad robothænderne berører, hvad instrumenterne gør, eller den kraft, de udøver, og kan ikke nødvendigvis høre, hvad der foregår i og omkring patienten. Ud over den direkte verbale kommunikation er alle de fornemmelser, som kirurger normalt er afhængige af i deres interaktion med patientkroppe og resten af holdet - herunder lugt og proprio- og alteroception, det vil sige deres kropslige fornemmelse af, hvor deres egen og andres kroppe er, og hvordan de bevæger sig, såvel som mange typer tegn, metakommunikation og generel multisemiotisk kommunikation - altså reduceret til at foregå igennem og afhængigt af én enkelt sans: den visuelle (for ikke at sige den televisuelle) og omhandler stort set kun det, der sker lige i operationsfeltet. Dette fænomen har været et hovedfokus i min hidtidige forskning i robotkirurgi: Hvad består robotensemblet af, hvordan fungerer det sensorisk, og hvordan håndterer kirurger manglen på sanselige indtryk, berøring og haptisk feedback - hvordan făr de en fornemmelse af ,kødelig berøring“'??

Teknologiudviklere har som sagt forsøgt at finde teknologiske løsninger på den manglende følesans. Min hypotese - eller position - er, at løsningen faktisk allerede findes inden for de eksisterende robotensembler: For at kompensere for den manglende følesans udvikler kirurgerne et haptisk syn. De lærer at føle med øjnene, i høj grad som en kropslig og ubevidst, tavs viden og som en videreudvikling og præcisering af en færdighed, som de, forslår jeg, allerede løbende har inkorporeret igennem hele deres øvrige kirurgiske og diagnostiske 
praksis. I robotensemblet bliver det haptiske syn den fremmeste og eneste følesans, hvormed de kan mærke densiteter, konturer og modstand fra de forskellige organ- og vævstyper - med deres øjne.

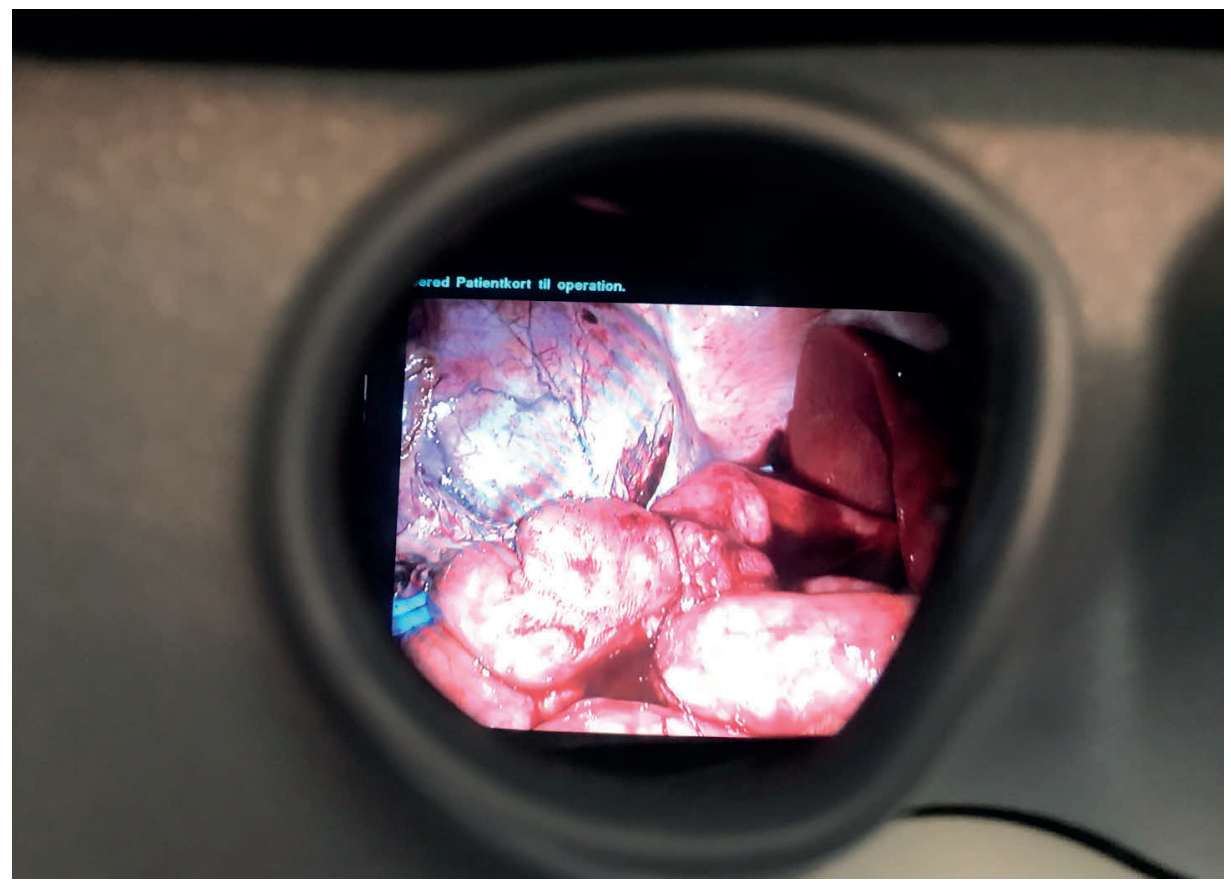

Det haptiske syn - det, at kunne føle berøring med øjnene - er et perfekt eksempel på Merleau-Pontys beskrivelse af syncestetik (2005): det sensoriske fænomen, at sanserne i praksis arbejder eller ligefrem smelter sammen. I klinikken og populærvidenskabeligt betegner „,synæstetik“ som regel diagnosen på, hvad man betragter som en sensorisk dysfunktion, nemlig at visse mennesker fejlagtigt blander ting sammen og fx forbinder bestemte farver med bogstaver og/eller tal. Det haptiske syn, som netop er en sammensmeltning af syn og følesans, kontrasterer således med den fremherskende anatomiske og taksonomiske ontologi, der ser sanserne som perfekt isolerede. Denne ontologi er igen forbundet med billedet af den fragmenterede krop og de anatomisk isolerede organer - en taksonomisk og funktionel kortlægning, som Leonardo da Vinci ${ }^{3}$ i øvrigt deltog i (Foucault 1972; Hillman \& Mazzio 1997). I det haptiske syn blandes sensoriske inputs: trykbølger (følesansens input) udgøres af elektromagnetiske lysbølger (synets input). Dermed har det haptiske syn en omvendt parallel i en anden medicinsk visualiseringsteknologi, nemlig et STM-mikroskop (Scanning Tunnelling Microscope) og dets efterfølger, ATM (Atomic Force Microscope). Begge danner et billede af et atom ved at berøre det med en tungstentip eller mekanisk sonde, „et møde, 
der engagerer følelsen af berøring frem for synet", som Barad skriver (2007:52; min oversættelse). Gennem tippens mekaniske berøring kan patologen således se, endnu et ekko af en cyborg'sk synæstetisk logik.

Den måde, den bioniske kirurg på robotstuen føler med sine hybridøjne, forbliver generelt tavs og ikke-ekspliceret. Under træningen nævnes problemet med manglende haptisk feedback af og til, men der er ingen specifikke moduler til optræning af haptisk syn i robotten, hvor det ellers er en helt fundamental og uundværlig sans. Og der er ingen ord til at beskrive fænomenet/sansen, blot hyppige opfordringer til øget opmærksomhed - ,,pas på, du trækker for hårdt!“, „,hold godt øje med milten“, „hov, skub ikke så hårdt til nyren med tippen!“‘. De digitale simuleringsværktøjer, der er indbygget i da Vinci-robotten, bruges til at træne og evaluere bevægelse og præcision, men haptisk syn som sådan trænes ikke. Ikke desto mindre synes kirurgerne at bero på deres forudgående erfaringer fra kikkertoperationer, hvor de også kan følge deres instrumenters og organers og vævs bevægelser på skærmen, men til gengæld har en direkte trykfølelse via instrumenterne fra det væv, de rører ved og hiver i. Når de arbejder sammen med robotten, udvikler de yderligere deres evne til at vurdere det tryk, de udøver, ud fra en række visuelle tegn, afhængigt af typen af indgreb, og hvilke vævstyper og organer de opererer på. For det første kan de direkte se, hvad det er, instrumenterne rører ved, og i nogen grad vurdere, hvor meget de trykker eller trækker - selv om de i starten under træningen kan komme til at skubbe for hårdt og perforere organer med hænderne eller trække tråden igennem hud eller væv, når de laver sting. For det andet reagerer nogle vævstyper på tryk ved at ændre farve, generelt på grund af ændret blodgennemstrømning, og dette bruges også som en indikation på tryk. For det tredje kan tryk på organer visuelt vurderes ved at se på lysrefleksioner på de blanke overflader, og dette synes også at være en indikation, som kirurgerne bruger. Men igen, alle disse visuelle færdigheder eksisterer som regel som tavs, kropsligt indlejret viden, selv om de af og til bliver ekspliciteret $\mathrm{i}$ træningssituationer og under supervision ved operationer såvel som i mine diskussioner med robotkirurger og kursusdeltagere. Men som sagt er der ikke et vokabular for det. Som John Berger minder os om, kommer synet før ordene (1972), men derudover undsiger synet sig også ofte ordene, og dette gælder også - og måske især - for det haptiske syn, som vi sjældent overhovedet bemærker, at vi bruger. 


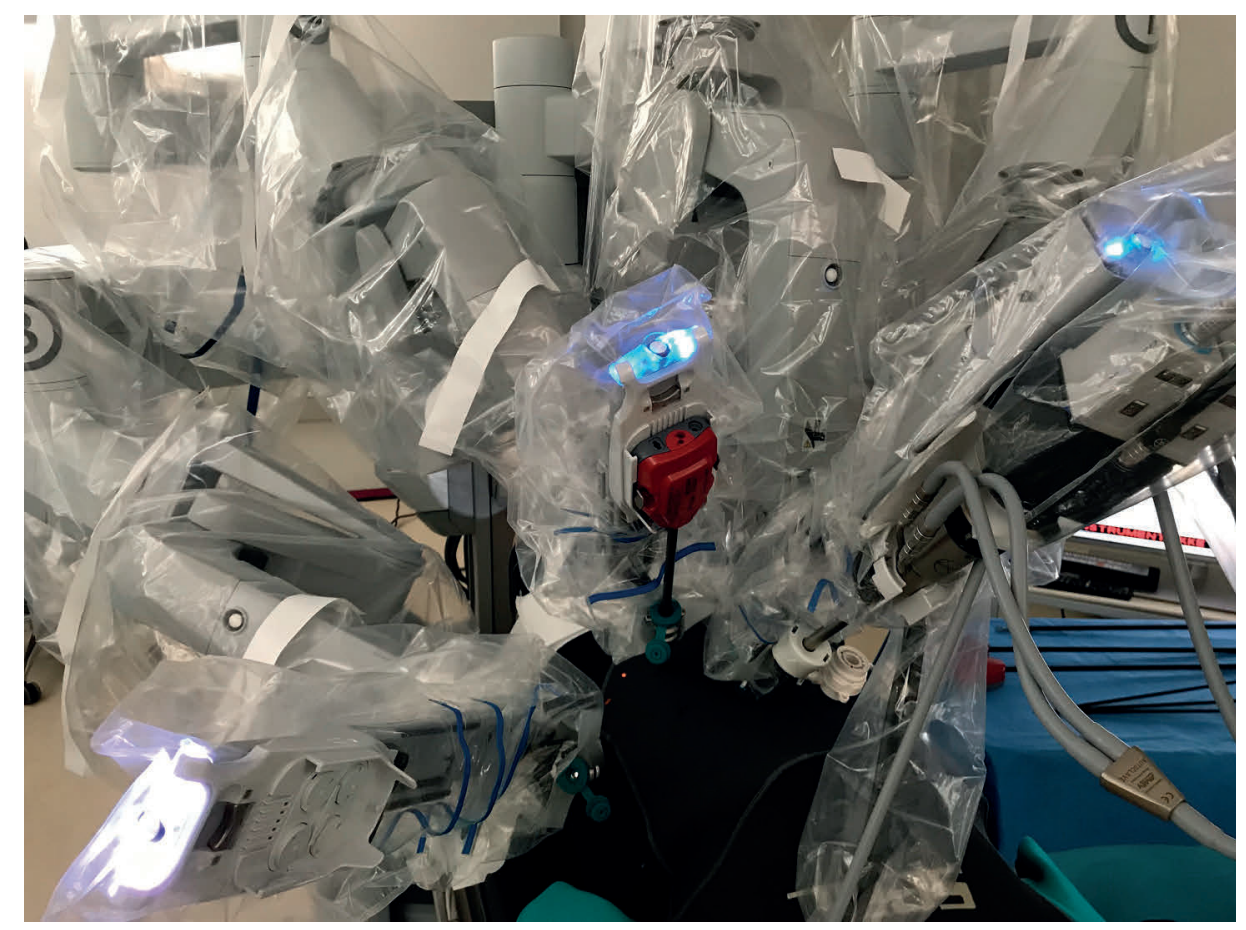

I robotkirurgicyborgen er menneskelige og metalliske kropsdele således forbundne og sammensmeltede, ligesom de forskellige sanseegenskaber, der er operative i cyborgen, er synæstetisk forbundne. Menneskets syn er en integreret del af ensemblet, og det er konfigureret af de mekaniske og optiske dele, som det fungerer igennem, og trænes yderligere til at udvikle en funktionel følelse af berøring.

I robotkirurgiensemblet er ikke kun sanserne sammenflettede og synæstetiske, men maskine- og menneskefærdigheder og -former konfigurerer hinanden indbyrdes. Det er en ægte cyborgfigur af kød og mekanik, der opløser dualismer og arbejder i menneskelig-materiel gensidighed. Gensidighed indebærer dog ikke nødvendigvis en symmetri i ensemblet (Suchman 2007), for robotten er konfigureret og betjent af mennesker. Men den har sine materielle specificiteter, som medkonfigurerer de kirurgiske praksisser og sanser i ensemblets arbejde. Haraway bruger netop cyborgfiguren og dens materiel-semiotiske egenskaber til at opløse dualismer og få øje på noget nyt om menneskelige sanser, færdigheder og socialitet (2016). Robot-kirurgi-ensemblet som cyborg bliver således et analytisk værktøj, en „talefigur“, til at pege på bredere samfundsmæssige sammenhænge og betydninger - fx økonomiske, teknologipolitiske, ansvarsmæssige, sundhedspolitiske - der udkrystalliseres i og omkring ensemblet.

Her har det handlet meget om at blotlægge de menneskelige sanser i ensemblet, og hvordan de konfigureres og ændres. Men der er andre relationer på spil om- 
kring ensemblet, som robotten introducerer. Robotten kan ikke „tænke“ og „se“, fx ved at udføre løbende billedanalyser og handle på dem, som de ansigtsgenkendelsessystemer, som jeg tidligere har forsket i. Men den har ikke desto mindre en form for visuel kontrolfunktion og autonomi, som introducerer andre aktører i de operative indgreb, og som spiller ind i ensemblets politiske økonomi. Operationerne optages nemlig løbende på video i konsollen, og disse videoer er direkte tilgængelige for Intuitives europæiske supportteam i Schweiz, som er koblet til robotten online og kan følge med i enhver bevægelse, der foretages inde i patienten. Og hvis kirurgen har logget ind på konsollen - hvilket nogle kirurger vælger ikke at gøre - er videoen og data fra operationen knyttet til vedkommendes profil. Så der er altså en anden type ,tele-vision“ på spil end kirurgens, og som løbende monitorerer og evaluerer robotensemblets handlinger og effektivitet. Det sker angiveligt i supportøjemed, men som med al anden overvågning er det brugbart også til andre og/eller kommende formål, i dette tilfælde, blandt andet kommercielle formål samt spørgsmål om firmaets ansvar i forbindelse med fejl og klager. For markedet er hårdt, der er konkurrenter på vej med nye kirurgiske robotter, og de økonomiske stakes er helt enorme, både på kortere og længere sigt. Brugen af AI (kunstig intelligens), AR (,augmented reality“ $)^{4}$ og en øget automatisering af arbejdsprocesser, analysearbejde og diagnosticering inden for sundhedsområdet er $\mathrm{i}$ rivende udvikling og kommer måske inden længe til at udgøre lige så store økonomiske og teknologiske satsningsområder som de militære. Og så bliver forståelsen af menneske-maskine-interaktioner, af de teknologiske specificiteter og processer og af, hvordan de spiller sammen med, former og formes af menneskelige sanser, analyseapparater og ageren - samt de teknologipolitiske spørgsmål, de bringer med sig, kun yderligere presserende.

\section{Noter}

1. Der er i 2020 i alt 26 robotter i aktivitet i hele Danmark, og de bruges især inden for urologi, gynækologi og mave-tarm-kirurgi; men flere andre specialer begynder i stigende grad at bruge robotter.

2. Jeg kalder det ,a sense of flesh“.

3. Da Vinci både kortlagde den menneskelige krop og byggede en menneskelignende robot, som netop har givet navn til Intuitives kirurgiske robot, da Vinci ${ }^{\circledR}$. Leonardos oprindelige tegninger (uden $\circledR$ ) var i 2002 grundlaget for en genbygning af hans ,robotridder“", og robotten er funktionel - dog ikke til kirurgi (Leonardo Davinci Robot Society 2020).

4. „Augmented reality“ kan fx på skærmen blande direkte billeder af et organ med MR-scanninger af organet, så kirurgen hele tiden kan se præcis, hvor der skal opereres. Teknologien arbejder i 3D og kræver enorm computerkraft, så scanningsbilledet hele tiden ligger præcist i forhold til det direkte billede, som ændrer sig, når kirurgen flytter sit kamera. 


\section{Litteratur}

Barad, Karen

2007 Meeting the Universe Halfway. Quantum Physics and the Entanglement of Matter and Meaning. Durham, NC: Duke University Press.

Berger, John

1972 Ways of Seeing. Harmondsworth: Penguin.

Bethea, Brian T., Allison M. Okamura, Masaya Kitagawa, Torin P. Fitton, Stephen M. Cattaneo, Vincent L. Gott, William A. Baumgartner \& David D. Yuh

2004 Application of Haptic Feedback to Robotic Surgery. Journal of Laparoendoscopic and Advanced Surgical Techniques 14(3):191-95. https://doi.org/10.1089/ 1092642041255441 .

Culmer, Peter, Ali Alazmani, Faisal Mushtaq, William Cross \& David Jayne

2020 Haptics in Surgical Robots. Handbook of Robotic and Image-Guided Surgery.

Elsevier Inc. https://doi.org/10.1016/b978-0-12-814245-5.00015-3.

Desai, Jaydip

2013 Haptic Feedback System Integration for a Prototype Robotic Surgical Unit.

Afhandling. Stevens Institute of Technology.

Ehrampoosh, Shervin, Mohi Dave, Michael A. Kia, Corneliu Rablau \& Mehrdad H. Zadeh

2013 Providing Haptic Feedback in Robot-Assisted Minimally Invasive Surgery.

A Direct Optical Force-Sensing Solution for Haptic Rendering of Deformable Bodies. Computer Aided Surgery 18(5-6):129-41. https://doi.org/10.3109/ 10929088.2013.839744.

Foucault, Michel

$1972 \quad$ Naissance de la Clinique. Paris: Presses Universitaires de France.

Haraway, Donna

2017 A Cyborg Manifesto. In: C. Wolfe (ed.): Manifestly Haraway. Pp. 3-90.

Minneapolis: University of Minnesota Press. https://doi.org/10.2307/3178066.

Hillman, David \& Carla Mazzio (eds)

1997 Introduction. Individual Parts. In: D. Hillman \& C. Mazzio (eds): The Body in Parts. Fantasies of Corporeality in Early Modern Europe. Pp. xii-xiii. London \& New York: Routledge.

Leonardo Davinci Robot Society

2020 Exploring the Robotic World of the Renaissance Master. The Robots. https: //www.leonardorobotsociety.org/the-robots.html. Læst 18.4.2020.

Merleau-Ponty, Maurice

2005 Phenomenology of Perception. London \& New York: Routledge.

Rangarajan, Karan, Heather Davis \& Philip H. Pucher

2020 Systematic Review of Virtual Haptics in Surgical Simulation. A Valid Educational Tool? Journal of Surgical Education 77(2):337-47. https://doi.org/10.1016/ J.JSURG.2019.09.006.

Suchman, Lucy

2007 Human-Machine Reconfigurations. Plans and Situated Actions. Cambridge:

Cambridge University Press. 